\title{
Development of Epoxy Matrix Artificial Stone Incorporated with Sintering Residue from Steelmaking Industry
}

\author{
Elaine Aparecida Santos Carvalho ${ }^{a}$, Vinícius Ribeiro Marques ${ }^{a}$, Rubén Jesus Sánchez Rodrigues ${ }^{a}$, \\ Carlos Eduardo Gomes Ribeiro ${ }^{b}$, Sergio Neves Monteiro ${ }^{c}$, Carlos Maurício Fontes Vieira ${ }^{a *}$ \\ a Advanced Materials Laboratory, Universidade Estadual do Norte Fluminense - UENF, \\ Av. Alberto Lamego, 2000, CEP 28013-602, Campos dos Goytacazes, RJ, Brazil \\ ${ }^{b}$ Mechanical Engineering Department, Instituto Federal do Espirito Santo - IFES, \\ Rodovia Cachoeiro Alegre, Km 05, CEP 29300-000, Cachoeiro de Itapemirim, ES, Brazil \\ ${ }^{c}$ Department of Materials Science, Instituto Militar de Engenharia - IME, \\ Praça General Tibúrcio, 80, Praia Vermelha, Urca, CEP 22290-270, Rio de Janeiro, RJ, Brazil
}

Received: December 14, 2014; Revised: November 11, 2015

The present work is part of an innovation research project aiming to develop artificial stone from industrial wastes. In principle, the project goal is to fabricate artificial stones with improved characteristics to be used as plates for housing and road construction. In this work, the specific industrial residue was an electrostatically precipitated powder obtained from the initial sintering stage of an integrated steelmaking plant. Plates were produce by vacuum vibro-compression of epoxy resin mixed with 80 and $85 \mathrm{wt} \%$ of this specific residue. After curing, the plates were characterized for physical parameters and mechanical properties. The microstructural aspect of the finishing surface was analyzed for both novel artificial stones by scanning electron microscopy. The results indicated that the $80 \%$ residue incorporated artificial stone is superior to the $85 \%$ residue incorporated and markedly stronger than a commercial artificial stone, incorporated with granite residue, with comparable density and water absorption. These characteristics favor the technical substitution of the presently investigated artificial for the commercial stone. In particular, based on wear tests, the residue incorporated artificial stone would be restricted to application as pavement in medium traffic roads.

Keywords: steelmaking industry, residue, artificial stone, technical characteristics

\section{Introduction}

Scientific and technological research works are being intensified around the world to permit the reuse of industrial residues that otherwise would be discarded to the ambient. In general these residues solid, liquid or gaseous need to be treated or recycled inside the own producing industry. In many cases, however, such as that of ornamental stones (marble, granite, etc) the residue cannot be locally treated or recycled and must be discarded in containing ponds or landfills. This represents serious risks associated with contamination by inappropriate transportation and handling ${ }^{1}$. Similar situation occurs for residues from steelmaking industries ${ }^{2}$.

In order to search solutions for this specific case of ornamental stone industrial sector, its corresponding residue has been investigated as possible by-product to fabricate composite materials as artificial stones ${ }^{3}$. This type of artificial stone would be a technically sound alternative to reduce both cost and environmental impact. Indeed, natural stones such as marble and granite not only generate a large amount of fragmented residues during cutting and polishing operations but are also brittle and can easy break, which generates more fragments. By contrast, the already commercial Stellar ${ }^{\mathrm{TM}}$ artificial marble composite is impervious, without stains and does not break easily. This is a consequence of the efficient

*e-mail: vieira@uenf.br adherence of the residue particles provided by the polymeric matrix resin, which also retains the penetration of liquids and prevents the formation and propagation of flaws and cracks ${ }^{4-6}$.

In the present work, the industrial residue investigated was not from the ornamental stone sector but from the steelmaking industrial sector. The current Brazilian year production of steel is of the order of 2.5 million tons. According to information presented by the Rio de Janeiro Industry Federation (FIRJAN) ${ }^{2}$, for each ton of produced steel, around $613 \mathrm{~kg}$ of residues are generated, from which $13 \%$ are fine powders. Therefore, an estimated 1.6 million ton of steelmaking residues, including 200 thousand tons of powders, are presently disposed in Brazil. Part of these powders corresponds to electrostatically precipitated fine residual particles that are the main material in this work. Indeed, it will be shown that the use of this residue as an epoxy composite to produce an artificial stone is associated not only with the valorization of an undesirable industrial waste but also to jobs opportunity based on the development of a novel material for civil construction. The objective was then to evaluate, for the first time, the possibility of fabricating artificial stone as an epoxy composite incorporated with a dust residue collected from the electrostatic precipitator of the sintering stage of a steelmaking plant. Plates of this composite were produced by vacuum vibro-compression with the intention of developing a new environmentally correct material with 
both competitive cost and acceptable quality for the market of ornamental stones. The vacuum vibro-compression technique was reported to promote an improvement in properties such as water absorption and mechanical strength ${ }^{7,8}$.

\section{Material and Methods}

The basic materials used in this work were a residue, with a maximum particle size of $0.1 \mathrm{~mm}$, collected at the eletrostatic precipitator of the sintering stage of the Arcelor Mittal integrated steelmaking plant located in Vitoria, ES, Brazil, and a commercial epoxy resin. The electrostatic precipitator powder residue (EPR) was mixed in amounts of 80 and $85 \mathrm{wt} \%$ with the still fluid diglycidyl ether of the bisphenol-A (DGEBA) epoxy resin mixed with phr 13, which is the stoichiometric fraction, of trietylene tetramine (TETA) hardener. The mixtures were poured under vacuum and $10 \mathrm{MPa}$ of pressure in a mold, which was subjected to the vibro-compression technique at $90^{\circ} \mathrm{C}$ for $20 \mathrm{~min}$ of cure. The molding process produced square plates with $100 \mathrm{~mm} \times 100 \mathrm{~mm}$ and $10 \mathrm{~mm}$ of thickness. These electrostatic powder residue incorporated artificial stone plates (EPRAP), in the amounts of 80 and 85\%, EPRAP 80 and EPRAP 85, respectively, were evaluated for their apparent density $\left(\rho_{a}\right)$, Equation 1, apparent porosity $\left(\eta_{a}\right)$, Equation 2, and water absorption $\left(\alpha_{\alpha}\right)$, Equation 3, according to the ABNT NBR 15845 norm $^{9}$. This norm served as the basis for fabrication of samples with dimensions of $50 \mathrm{~mm} \times 50 \mathrm{~mm} \times 50 \mathrm{~mm}$. These samples were dried in a stove at $70^{\circ} \mathrm{C}$ for 24 hours and then placed inside a desiccator until measurements. Then, distilled water was added in a flask until $1 / 3$ of the samples' height. After 4 hours, more water until $2 / 3$ of the height was added and, after another $4 \mathrm{~h}$, complete submersion of the samples during 40 hours. The samples were then weighed both submerged (sub), water saturated (sat) and dried (sec). Properties were obtained through the following equations:

$$
\begin{aligned}
& \rho_{a}=\frac{M_{s e c}}{\left(M_{s a t}-M_{s u b}\right)} \times 1000 \\
& n_{a}=\frac{\left(M_{s a t}-M_{s e c}\right)}{\left(M_{s a t}-M_{s u b}\right)} \times 100 \\
& \alpha_{a}=\frac{\left(M_{s a t}-M_{s e c}\right)}{\left(M_{s a t}-M_{s u b}\right)} \times 100
\end{aligned}
$$

where $M_{\text {sec }}$ is the dry mass; $M_{\text {sat }}$ the water saturated mass, and $\mathrm{M}_{\text {sub }}$ the submerged (hydrostatic scale weight) mass.

The mechanical strength was evaluated at room temperature (RT) by three points bending tests in a model 5582 Instron machine. For these tests, the recommendations for agglomerated stones of the Spanish EN 14617-2 norm ${ }^{10}$ as well as the F annex of the Brazilian norm ABNT NBR $15845^{[9]}$ were followed. Ten prismatic specimens with dimensions of $100 \mathrm{~mm} \times 25 \mathrm{~mm} \times 10 \mathrm{~mm}$ were used for each condition of these flexural tests. The average stress and corresponding standard deviation were calculated.

Amsler type of wear tests were conducted in two samples cut out of each EPRAP with reduced dimensions of $70 \mathrm{~mm} \times 70 \mathrm{~mm}$. These wear tests were RT performed in a rotatory hard circular track using normalized sand as abrasion material. In the wear test, a load of $66 \mathrm{~N}$ was applied on the specimen while maintaining a sand flow of $72 \pm 6 \mathrm{~cm}^{3} / \mathrm{min}$ onto the rotary track. After 250 turns, which corresponds to a total circuit of $500 \mathrm{~m}$, the specimen was weighed. This was done again after 500 turns (total $1000 \mathrm{~m}$ ). Amsler wearing was given in terms of thickness reduction after $500 \mathrm{~m}$ and $1000 \mathrm{~m}$ of trajectory according to the NBR 12.042:2012 norm ${ }^{11}$. The EPRAP physical parameters and mechanical results were compared to those obtained with similar test procedure in an artificial Stellar ${ }^{\mathrm{TM}}$ commercial ornamental stone, supplied by the Ecologicstone firm.

The surface microstructural aspect of gold sputtered samples of the distinct EPRAPs were analyzed by scanning electron microscopy (SEM) in a model JSM-6460 LV Jeol microscope, operating with secondary electrons at $20 \mathrm{kV}$.

\section{Results and Discussion}

Table 1 presents the results of density, water absorption, apparent porosity and density of the materials. The EPRAPs have similar or less water adsorption and apparent porosity than those of the Stellar ${ }^{\mathrm{TM}}$ stone, with no significant influence of the type of residues. By contrast, in Table 1 and Figure 1

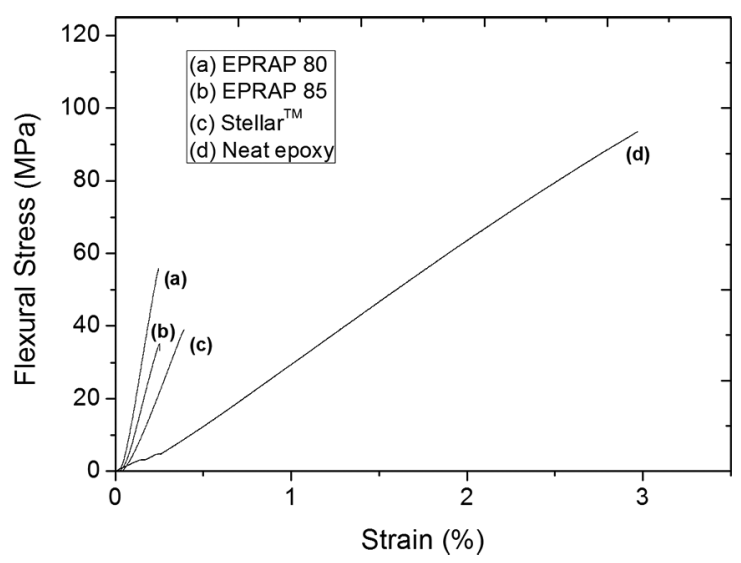

Figure 1. Flexural strength versus deflection strain curves for: EPRAP 85, EPRAP 80, neat epoxy and commercial ornamental stone.

Table 1. Density, water absorption, apparent porosity and flexural strength of sintering electrostatic precipitator artificial stone plates (EPRAP), commercial artificial stone, epoxy and electrostatic precipitator residue (EPR).

\begin{tabular}{ccccc}
\hline Specimen & $\begin{array}{c}\text { Density } \\
\left(\mathbf{g} / \mathbf{c m}^{\mathbf{3}}\right)\end{array}$ & $\begin{array}{c}\text { Water absorption } \\
\mathbf{( \% )}\end{array}$ & $\begin{array}{c}\text { Apparent porosity } \\
\mathbf{( \% )}\end{array}$ & $\begin{array}{c}\text { Flexural Strenght } \\
\mathbf{( M P a )}\end{array}$ \\
\hline EPRAP 85 & $2.73 \pm 0.03$ & $0.24 \pm 0.12$ & $0.65 \pm 0.23$ & $41.70 \pm 4.08$ \\
EPRAP 80 & $2.68 \pm 0.03$ & $0.17 \pm 0.04$ & $0.45 \pm 0.12$ & $57.57 \pm 3.21$ \\
Stellar ${ }^{\mathrm{MM}}$ & $2.38 \pm 0.04$ & $0.18 \pm 0.04$ & $0.44 \pm 0.10$ & $36.61 \pm 2.48$ \\
Epoxy & $1.16 \pm 0.05$ & - & - & $93.59 \pm 4.7$ \\
EPR & $2.89 \pm 0.04$ & - & - & - \\
\hline
\end{tabular}


it can be seen that the flexural strength was improved by the addition of the electrostatic precipitator residue (EPR).

The EPRAPs' densities were higher than that of Stellar ${ }^{\mathrm{TM}}$ stone, which was due to the residue incorporation. Artificial stones with addition of other types of residue and similar process methodologies show similar effects on density. Lee et al. ${ }^{12}$ report artificial stones with density of $2.11 \mathrm{~g} / \mathrm{cm}^{3}$ fabricated from glass and a granite residue, which have lower density than that of EPR in the present work. Santos et al. ${ }^{13}$ also reported a lower density value of $2.40 \mathrm{~g} / \mathrm{cm}^{3}$. As for the water absorption and apparent porosity, Table 1, the EPRAP 80 displays lower values, similar to those of the Stellar ${ }^{\mathrm{TM}}$ stone. Both the water absorption and the porosity could be associated with the microstructure of the artificial stone. This depends on the process variables and particles size distribution of incorporated residue and other less important contributions.

As shown in Figure 1, The EPRAP samples presented a higher flexural modulus than the Stellar ${ }^{\mathrm{TM}}$ and the epoxy resin. This could be a consequence of the more rigid EPR particles $^{12}$ but should also be analyzed in terms of the microstructure effect on the mechanical properties. As for the EPRAPs formulations, one must consider a different behavior. The efficient epoxy matrix between residue particles improves the mechanical properties in EPRAP 80 stone with $20 \mathrm{wt} \%$ of epoxy content. In this stone, it could be observed a more uniform region in the fracture between electrostatic precipitator residue particles, as pointed by arrows in Figure 2b.

The morphology observed in both samples of EPRAPs at the fracture region, Figure 2, as well as Stellar ${ }^{\mathrm{TM}}$ were in agreement with the density and apparent porosity presented in Table 1. The fracture regions of the $15 \%$ and $20 \mathrm{wt} \%$ epoxy samples display the existence of cavities and/or pores. The relevant differences, however, were the epoxy uniformity and particles contact aspects. Apparently, these differences were the main responsible for the lower flexural modulus of EPRAP 85 as compared to EPRAP 80 artificial stones.

Moreover, the flexural strength, Table 1, of both EPRAP $85(41.70 \mathrm{MPa})$ and EPRAP $80(51.57 \mathrm{MPa})$ stones were significantly lower than that of the neat epoxy (93.59 MPa). In principle, this was expected as a consequence of the artificial stone microstructure, in which the polymer phase is not continuous but full of porosity, which caused a reduction in the mechanical properties ${ }^{13}$, as compared to the neat epoxy.

The flexural rupture stress data reported in the litterature ${ }^{14-16}$ for artificial stones with similar contents of the present EPRAPs, but employing calcareous marble particles, were found to vary between $16-46 \mathrm{MPa}$. The difference in values might be attributed to microstructure flaws, such as voids and porosities.

The wear test is extensively used to evaluate the performance of a given material, including hard surface for both pedestrian and vehicles pavements. In this test, the volume loss of a stone for house or road construction causes changes in the mechanical properties as well as brightness and color of the surface ${ }^{17}$. Table 2 shows the abrasive wear for the EPRAPs and the commercial Stellar ${ }^{\mathrm{TM}}$ stone. In this table it is seen that the commercial stone is around $30 \%$ more

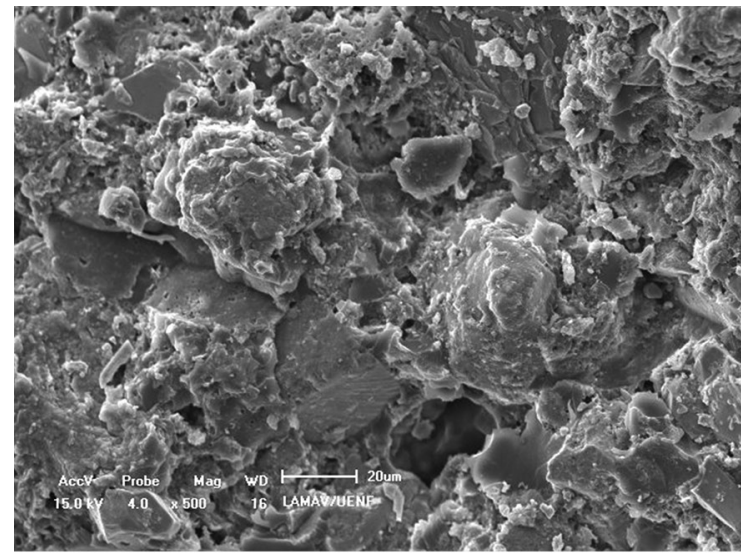

(a)

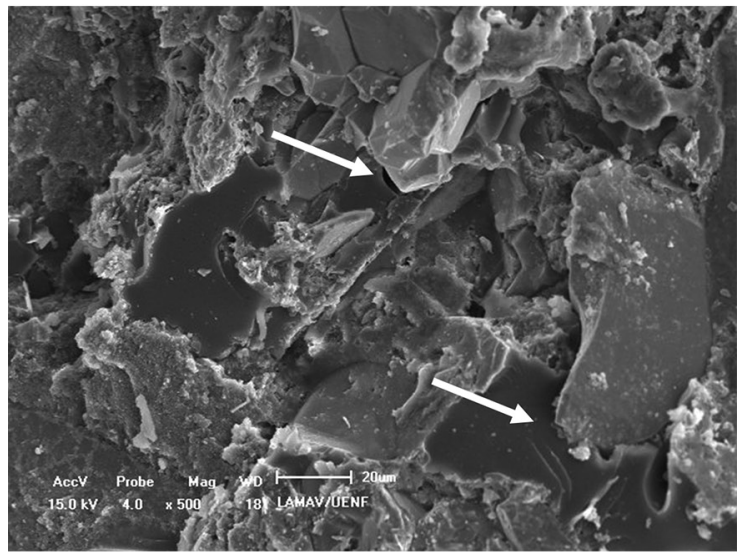

(b)

Figure 2. SEM fractographs of the materials EPRAP 85 (a) and EPRAP 80 (b).

Table 2. Amsler wearing associated with thickness reduction of EPRAPs and Stellar ${ }^{\mathrm{TM}}$.

\begin{tabular}{ccc}
\hline \multirow{2}{*}{ Material } & \multicolumn{2}{c}{ Abrasive Wear $(\mathbf{m m})$} \\
\cline { 2 - 3 } & $\mathbf{5 0 0 ~} \mathbf{~}$ & $\mathbf{1 0 0 0} \mathbf{~}$ \\
\hline EPRAP 85 & 1.34 & 2.52 \\
EPRAP 80 & 1.04 & 2.16 \\
Stellar $^{\mathrm{TM}}$ & 0.70 & 1.53 \\
\hline
\end{tabular}

wear resistant than the EPRAPs. In the case of EPRAP 85, the limited amount ( $15 \mathrm{wt} \%$ ) of epoxy is responsible for the greater abrasive wear due to the loss of EPR particles that might not be well adhered to the relatively small amount of polymeric phase.

Here is important to mention that there is no wear specification in Brazilian norms. In other words, there is no limit imposed by norm to the wearing reduction in abrasive tests. Frasão \& Farjallat $^{18}$ suggested a maximum limit of $1 \mathrm{~mm}$ for reduction in Amsler wearing. Chiodi \& Rodrigues ${ }^{19}$ proposed different wearing reduction specifications to be applied as technological parameter in calcareous stones for horizontal pavement plates. According to these authors, light traffic pavements should have Amsler wearing less than 


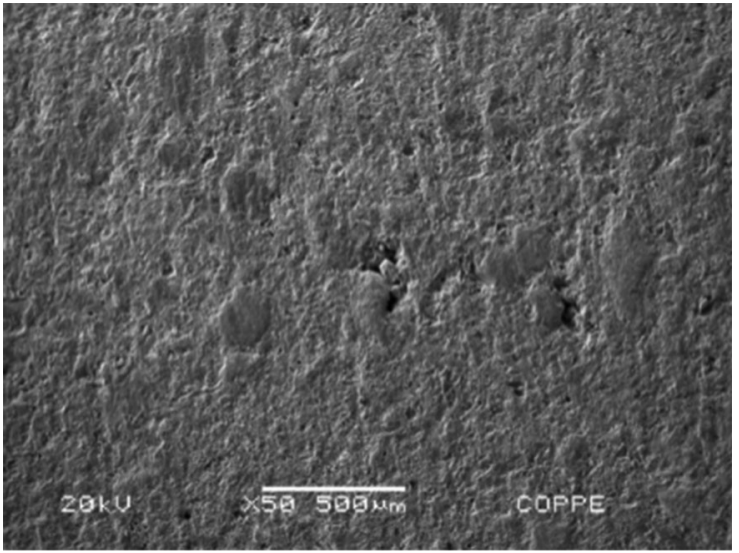

(a)

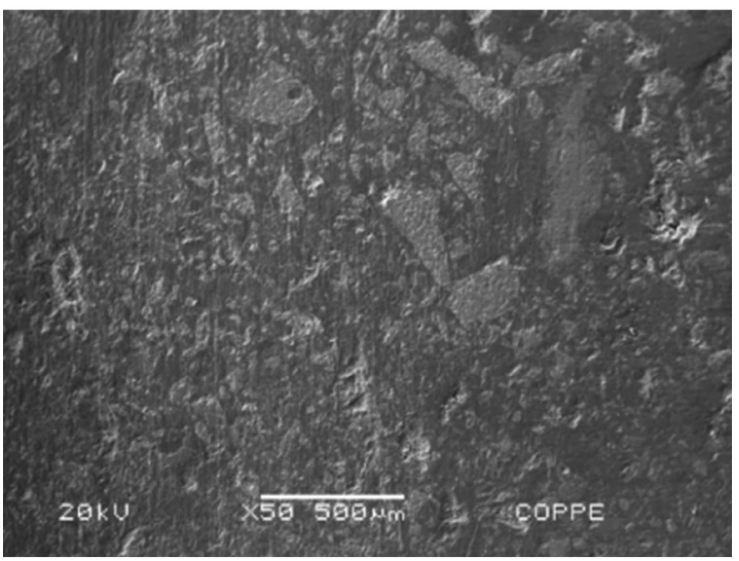

(b)

Figure 3. SEM micrograph of the EPRAP 85 (a) and EPRAP 80 (b) polished surfaces.

$6 \mathrm{~mm}$ while medium traffic less than $3 \mathrm{~mm}$ and heavy traffic less than $1.5 \mathrm{~mm}$. Following this proposal, the commercial Stella ${ }^{\mathrm{TM}}$ stone could be used in any kind of traffic. However, the EPRAPs would be restricted for application as pavements in medium or light traffic roads.

It is also relevant to mention that Ribeiro ${ }^{20}$ found a greater reduction in thickness of an artificial stone fabricated with limestone (calcareous) particles incorporated into a polymeric matrix. The author reported reductions of 5.23 and $8.83 \mathrm{~mm}$ after, respectively, 500 and $1000 \mathrm{~m}$ of wear test. The artificial stone investigated by Ribeiro ${ }^{20}$, however, presented relatively high porosity and weak particle/matrix interfacial bonding caused by a non-reactive solvent. This justified the large thickness reduction observed.

Figure 3 shows by SEM the polished surface aspect of both EPRAPs 85 and EPRAP 80. Sensible microstructural differences can be detected between the two materials. In addition to a greater amount of residue particles, as expected, the EPRAP 85 in Figure 3a also reveals more porosity in its epoxy matrix than the EPRAP 80 in Figure $3 \mathrm{~b}$. As aforementioned, this is a consequence of a comparatively more difficult molding operation due to an excess of residue in the EPRAP 85. The lack of adhesion between the residue

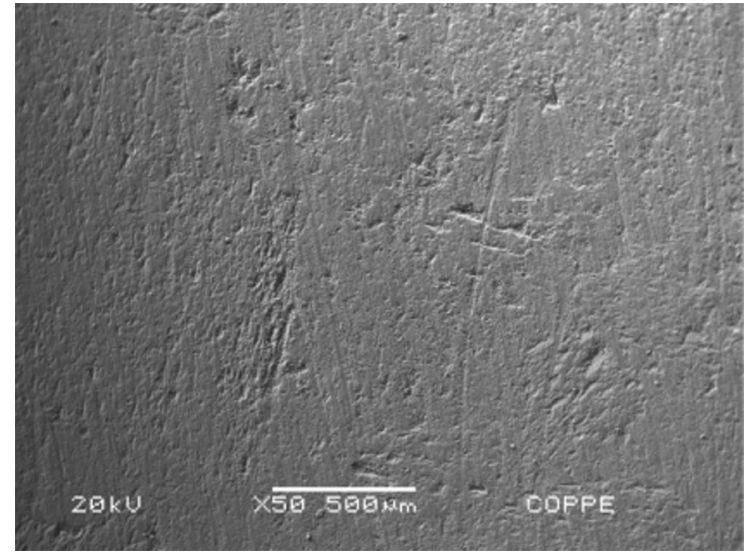

Figure 4. SEM micrograph of the polished surface of commercial Stellar ${ }^{\mathrm{TM}}$ artificial stone.

particles and the epoxy resin gives rise to pores that impairs the water absorption and the mechanical properties. On the contrary, EPRAP 80 in Figure 3 b reveals a more consistent microstructure with less amount of pores, which justify its higher flexural modulus in Table 1. Figure 4 shows the polished surface of the Stellar ${ }^{\mathrm{TM}}$ commercial stone. In this figure, it is observed a smooth surface, which is associated with good physical properties.

\section{Summary and Conclusions}

Artificial stones, EPRAP 85 and EPRAP 80, with DGEBA/TETA epoxy matrices incorporated, respectively, with 85 and $80 \mathrm{wt} \%$ of residue, collected from the electrostatic precipitator in the sintering sector of an integrated steelmaking plant, were for the first time developed and characterized.

- The water absorption and porosity of these novel artificial stones, EPRAPs, were found to be similar to those of a Stellar ${ }^{\mathrm{TM}}$ commercial artificial stone made with granite residues.

- The EPRAPs flexural strengths were superior not only to that of the Stellar ${ }^{\mathrm{TM}}$ but also to the flexural strengths obtained in other conventional artificial stones incorporated with residues from marble and glass industries.

- In particular, the EPRAP 80 with 20 wt\% of epoxy resin, displays a microstructure with less porosity and a wear resistance enough to be used in pavements supporting medium or light traffic.

\section{Acknowledgements}

The authors thank the Brazilian agencies: CNPq, CAPES, and FAPERJ for financing this research and for providing scholarships to E.A.S.C, V.R.M and C.E.G.R co-authors. It is also acknowledged the permission to use the SEM facility of the PEMM/COPPE of the Federal University of Rio de Janeiro. 


\section{References}

1. Gonçalves JP, Moura WA and Dal Molin DC. Evaluation of granite residue from cutting operation, as addition, on the mechanical properties of concrete (in Protuguese). Ambiente Construído. 2002; 2(1):53-68.

2. Federation of State of Rio de Janeiro Industries - FIRJAN. Rio, environment, technology and sustainability solutions in the Brazilian steelmaking sector. Rio de Janeiro: FIRJAN; 2009. In Portuguese.

3. Ribeiro CEG, Rodríguez RJS, Vieira CMF, Carvalho EA, Cândido VS and Monteiro SN. Fabrication of artificial stone from marble residue by resin transfer molding. Materials Science Forum. 2014; 775-776:336-340. http://dx.doi.org/10.4028/ www.scientific.net/MSF.775-776.336.

4. Ribeiro CEG, Rodríguez RJS, Vieira CMF, Carvalho EA, Cândido VS and Monteiro SN. Production of synthetic ornamental marble as a marble waste added polyester composite. Materials Science Forum. 2014; 775-776:341-345. http://dx.doi.org/10.4028/ www.scientific.net/MSF.775-776.341.

5. Ribeiro CEG, Rodriguez RJS and Vieira CMF. Production of ornamental compound marble with marble waste and unsaturated polyester. In. Proceedings of the Extraction \& Processing Division (EPD) Congress 2014, 143rd Annual Meeting \& Exhibition ( ${ }^{\mathrm{TM}} L$ 2014); 2014; San Diego, EUA. Hoboken: Wiley/TMS, 2014. p. 129-194.

6. Molinari EJ. Reuse of natural stone residues for the development of thermo set polymer matrix composite in the fabrication of industrial stones. [Dissertation]. Florianópolis: Federal University of Santa Catarina; 2007. In Portuguese.

7. Ming-Yu L, Chun-Han K, Fang-Chih C, Shang-Lien L, JyhDong L, Ming S, et al. Artificial stone slab production using waste glass, stone fragments and vacuum vibratory compaction. Cement and Concrete Composites. 2008; 30(7):583-587. http:// dx.doi.org/10.1016/j.cemconcomp.2008.03.004.

8. Lee DJ and Shin IJ. Effects of vacuum, mold temperature and cooling rate on mechanical properties of press consolidated glass fiber/PET composite. Composites. Part A, Applied Science and Manufacturing. 2002; 33(8):1107-1114. http://dx.doi. org/10.1016/S1359-835X(02)00051-9.

9. Brazilian Association of Technical Norms-ABNT. ABNT NBR 15845-10: stones for linning: test methods. Rio de Janeiro: ABNT; 2010. In Portuguese.
10. Spanish Association of Standards and Certification. UNE-EN 14617-2-08: test methods part 2: determination of the flexural strength. Madrid: UNE-EN; 2008. In Spanish.

11. Brazilian Association of Technical Norms-ABNT. ABNTNBR 12.042-12: inorganic material - determination of abrasion wearing. Rio de Janeiro: ABNT; 2012.

12. Lee M-Y, Ku C-H, Chang F-C, Lo S-L, Lin J-D, Shan M-Y, et al. Artificial stones lab production using was glass, stone fragments and vacum vibratory compaction. Cement and Concrete Composites. 2008; 30(7):583-587. http://dx.doi.org/10.1016/j. cemconcomp.2008.03.004.

13. Santos JPL, Rosa LG and Amaral PM. Temperature effects on mechanical behaviour of engineered stones. Construction \& Building Materials. 2011; 25(1):171-174. http://dx.doi. org/10.1016/j.conbuildmat.2010.06.042.

14. Dalpiaz G. Study of the effect of mineral fillers in particulates polypropylene matrix composites. [Thesis]. Porto Alegre: Universidade Federal do Rio Grande do Sul; 2006. In Portuguese.

15. Gunduz G. Processing of unsaturated polyester. In: Cheremisinoff NP, editor. Advanced polymer processing operations. Westwood: United States of America; 1998. p. 1-38.

16. Borsellino C, Calabrese L and Di Bella G. Effects of powder concentration and type of resin on the performance of marble composite structures. Construction \& Building Materials. 2009; 23(5):1915-1921. http://dx.doi.org/10.1016/j. conbuildmat.2008.09.005.

17. Karaca Z, Hacımustafaoğlu R and Gökçe MV. Grain properties, grain boundary interactions and their effects on the characteristics of marbles used as building stones. Construction \& Building Materials. 2015; 15:166-171. http://dx.doi.org/10.1016/j. conbuildmat.2015.05.023

18. Frasão EB and Farjallat JES. Technological characteristics of the principal Brazilian silicate stones used as covering. In: Proceedings of the 1st International Conference of Natural Stone; Lisboa, Portugal. Lisboa: Ministry of Trade and Tourism; 1995. p. 47-58.

19. Chiodi C Fo and Rodriguez HP. Guide application of stones in coverings. São Paulo: Abirochas; 2009. p. 118.

20. Ribeiro CEG. Production of artificial Stone using a residue from the marble industry in polyester matrix. [Thesis]. Campos dos Goytacazes: State University of the Northern Rio de Janeiro; 2011. In Portuguese. 